\title{
Acute haemodynamic and metabolic effects of dopexamine, a new dopaminergic receptor agonist, in patients with chronic heart failure
}

\author{
J R DAWSON, D S THOMPSON, M SIGNY, S M JUUL, P TURNBULL, \\ B S JENKINS, M M WEBB-PEPLOE
}

From the Department of Cardiology, St Thomas' Hospital, London

SUMMARY Dopexamine, a new compound with postjunctional dopamine receptor activating and beta adrenoceptor agonist properties, was given to 10 patients with chronic heart failure at diagnostic cardiac catheterisation to investigate its acute haemodynamic and metabolic effects. The drug was administered by intravenous infusion in three incremental doses and produced significant dose related increases in cardiac index, stroke volume index, and heart rate and falls in systemic vascular resistance and left ventricular end diastolic pressure; aortic and pulmonary artery pressures were unchanged. Isovolumic phase (max $\mathrm{dP} / \mathrm{dt}$ and $\mathrm{KVmax}$ ) and ejection phase (peak aortic blood velocity, maximum acceleration of blood, and maximum rate of change of power with time during ejection) indices of myocardial contractility were all increased by dopexamine but these changes were hard to interpret in the presence of an increase in heart rate. Myocardial efficiency and ejection fraction were both increased and left ventricular end diastolic and end systolic volumes fell. These largely beneficial changes were achieved without a statistically significant increase in myocardial oxygen consumption or disturbance of myocardial metabolic function. Dopexamine was well tolerated but tremor was reported by two patients at the intermediate dose and mild chest pain by two patients at the high dose.

Dopamine is well established in the management of acute or acute on chronic heart failure. ${ }^{12}$ The clinical value of dopamine, however, is often limited by alpha adrenoceptor mediated peripheral constriction, ${ }^{34}$ which increases the load faced by the left ventricle during ejection. Consequently myocardial oxygen demand increases and myocardial ischaemia may be induced in patients with coronary artery disease. $^{5}$

Dopexamine (Fisons Pharmaceutical Division) is a recently synthesised compound which is structurally related to dopamine (Fig. 1). Like dopamine it can only be administered intravenously. In vitro and in vivo animal experiments show that the drug activates postjunctional dopamine receptors (equipotently with dopamine), has substantial beta ${ }_{2}$ adrenoceptor agonist activity, has no beta ${ }_{1}$ adrenoceptor agonist activity, and, unlike dopamine, is inactive at

Requests for reprints to Dr J R Dawson, Department of Cardiology, St Thomas' Hospital, London SE1 7EH.

Accepted for publication 21 May 1985 the alpha adrenoceptors. ${ }^{67}$ This pharmacological profile suggests that dopexamine will produce haemodynamic improvement in patients with heart failure and because of its theoretical superiority to dopamine is worthy of evaluation. The haemodynamic and metabolic effects of dopexamine were evaluated in 10 patients with severe chronic heart failure.

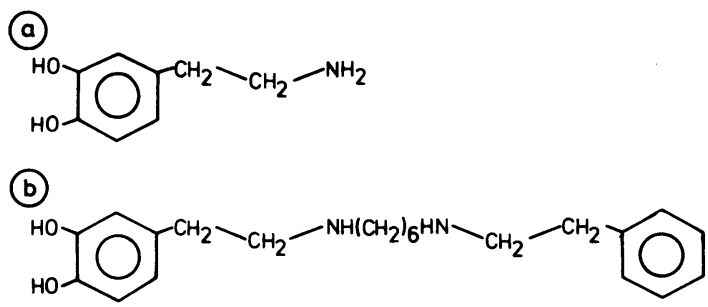

Fig. 1 Chemical structure of dopamine (a) and dopexamine (b). 


\section{Patients and methods}

\section{PATIENTS}

Ten patients (nine men and one women, mean age 54 (range 44-69)) with chronic heart failure undergoing diagnostic cardiac catheterisation participated in the study. Each patient gave written consent and the study protocol was approved by the hospital ethics committee. All patients were severely limited by dyspnoea (class 3, New York Heart Association), had radiographic evidence of cardiomegaly and pulmonary venous congestion, and required large maintenance doses of diuretics. Five patients were in sinus rhythm and five had atrial fibrillation. Heart failure was due to dilated cardiomyopathy in four patients, coronary artery disease in five patients, and in one patient it was associated with poor left ventricular function after mitral valve replacement (the mitral prothesis was found to be functioning normally).

\section{INSTRUMENTATION}

Patients were studied after an overnight fast. One hour before catheterisation, diazepam $(10 \mathrm{mg})$ was give intramuscularly and at the same time heparin (45 units $/ \mathrm{kg}$ ) was given intravenously to minimise the effect of a subsequent dose of heparin upon free fatty acid concentrations. ${ }^{8}$ Right atrial and pulmonary artery pressures were measured by means of a fluid filled coaxial catheter system from the right femoral vein. Cardiac output was measured in triplicate by the indocyanine green dye dilution method and an earpiece densitometer (Nihon Kohden MLC 4100). ${ }^{9}$ The coronary sinus was cannulated with a Ganz catheter (Wilton Webster Inc) from a left antecubital vein and its position was confirmed by the injection of contrast medium. This allowed coronary sinus blood to be sampled and coronary sinus flow to be measured. The long sheath technique ${ }^{10}$ was used to position a Millar multisensor catheter from the right femoral artery in the left heart for the measurement of high fidelity left ventricular and aortic pressures and aortic blood velocity. A pigtail catheter from the left femoral artery was positioned in the left ventricle for blood sampling and injection of contrast medium. The sternal angle was used as the zero reference point for pressure measurements. The electrocardiogram (standard lead II) was monitored throughout the study period.

\section{PROTOCOL}

Routine treatment for heart failure was not given to patients on the morning of the study. Conventional right and left heart catheterisation was performed. Another dose of heparin (45 units/kg) was given immediately after arterial catheterisation. Mea- surements were made of pressure, and coronary arteriography and left ventricular cineangiography (right anterior oblique projection) were performed. After this initial diagnostic procedure the patient's haemodynamic state was allowed to stabilise for 20 minutes before the start of the study. During the study period right atrial, pulmonary artery, left ventricular, and aortic pressures, and cardiac output and aortic blood velocity were measured simultaneously, and left ventricular and coronary sinus blood was sampled. Dopexamine was administered by continuous intravenous infusion. The dose was increased at intervals of 10 minutes. The doses of 1 , 3 , and $6 \mu \mathrm{g} / \mathrm{kg} / \mathrm{min}$ are described as low, intermediate, and high doses respectively. Measurements were made during an initial control period and five minutes after each dose increment. After we had completed measurements at the highest dose of the drug tolerated by each patient we performed a second left ventricular cineangiogram during drug infusion.

DATA ANALYSIS

Pressure signals, the aortic blood velocity signal, and the electrocardiogram were displayed on a twelve channel Cambridge recorder. Recordings of $18 \mathrm{sec}-$ onds duration were selected and converted to digital form by computer (Varian 600E) and then stored on disc for subsequent off line editing and analysis. The high fidelity left ventricular pressure records were used to derive the isovolumic phase indices of myocardial contractility: $\mathrm{dP} / \mathrm{dt},{ }^{11}$ the maximum rate of pressure increase with time; and $\mathrm{KVmax}^{12}$ the product of the series elastic stiffness constant and the velocity of contractile element shortening at zero load. The aortic velocity signal was used to derive the ejection phase indices of myocardial contracility: peak aortic blood velocity, ${ }^{13}$ and maximal acceleration of blood during ejection. ${ }^{14}$ The aortic velocity signal was converted to volumetric flow by multiplication by the aortic cross sectional area, which had been determined by echocardiography. This flow signal was then calibrated in vivo by setting the signal of the stroke volume to equal that of the stroke volume derived from simultaneously performed indocyanine green dye measurements. Maximum rate of change of power with time (dPower/dt) ${ }^{15}$ was determined from the first derivative of the product of instantaneous aortic pressure and flow. Cardiac $\underset{\gamma}{ }$ index, stroke volume index, and systemic and pulmonary vascular resistances were calculated from standard formulas.

Blood oxygen content was measured by a LEX 02 CON-TL. Left ventricular and coronary sinus blood samples were analysed for concentrations of lactate and pyruvate, ${ }^{16}$ hydroxybutyrate and aceto- 
acetate, ${ }^{17}$ glycerol, ${ }^{18}$ free fatty acids, ${ }^{19}$ and glucose. The extraction ratio of a substrate is defined as the difference between the arterial and coronary sinus concentration of that substrate expressed as a percentage of the arterial concentration of the substrate. Coronary sinus blood flow was measured by continuous thermodilution. ${ }^{20}$ Myocardial oxygen consumption was calculated as the product of coronary sinus flow and the arterial coronary sinus oxygen difference. Myocardial efficiency, relating the external work performed by the left ventricle (left ventricular minute work) to myocardial oxygen consumption, was estimated according to the formula of Bing and Michal. ${ }^{21}$

Left ventricular cineangiograms were analysed by a computer light pen system to give left ventricular volumes and ejection fraction.

\section{STATISTICAL ANALYSIS}

Results are expressed as means (SEM). Analysis of variance was used to test for treatment effect. If this was significant $(p<0.05)$ for a particular variable then the least significant difference method ${ }^{22}$ was used to determine the significance of differences between control and the three doses and among the three doses.

\section{Results}

\section{HAEMODYNAMICS}

The data for measured and calculated haemodynamic variables are shown in Table 1 and in Fig. 2 . When variables were significantly changed by dopexamine from their control value, the magnitude of the change was found to be dose related. Heart rate was increase from a control value of 90(5) beats $/ \mathrm{min}$ to $120(6)$ beats $/ \mathrm{min}$ at the high dose $(33 \%$, $\mathrm{p}<0.001$ ). Cardiac index rose in all patients from a control mean of $1 \cdot 4(0 \cdot 1) 1 / \mathrm{min} / \mathrm{m}^{2}$ to $3 \cdot 1(0 \cdot 4)$ $1 / \mathrm{min} / \mathrm{m}^{2}$ at the high dose $(121 \%, \mathrm{p}<0.001)$. Stroke volume index increased from a mean of 16(2) $\mathrm{ml} / \mathrm{beat} / \mathrm{m}^{2}$ to $26(4) \mathrm{ml} /$ beat $/ \mathrm{m}^{2}$ at the high dose
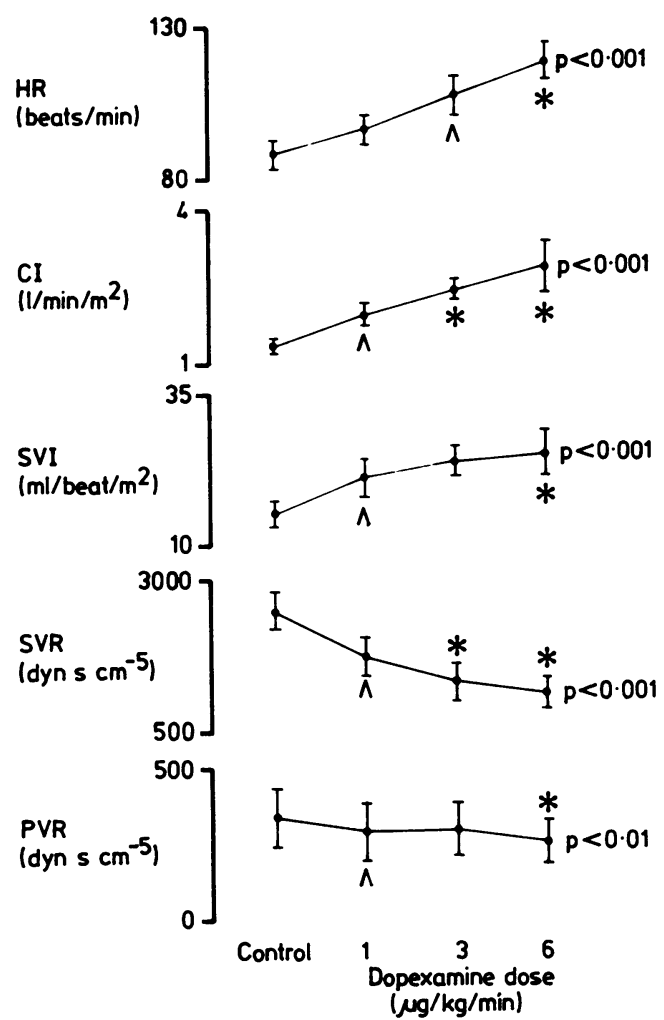

Fig. 2 Effect of treatment with three incremental doses of dopexamine on heart rate $(H R)$, cardiac index $(C I)$, stroke volume index (SVI), systemic vascular resistance (SVR), and pulmonary vascular resistance (PVR). Significance of the treatment effect is shown. The arrow head indicates the first dose at which a change from control was significant $(p<0.05)$. Asterisks indicate when the effect of the dose was significantly different from the effect of a preceding dose $(p<0.05)$.

$(63 \%, \mathrm{p}<0.001)$. Both aortic and pulmonary artery pressures were essentially unchanged by dopexamine administration and therefore, because flow was increased, calculated systemic and pulmonary

Table 1 Effects (mean (SE)) of an intravenous infusion of dopexamine at three incremental doses on aortic pressure $(A P)$, pulmonary artery pressure $(P A P)$, left ventricular end diastolic pressure (LVEDP), and mean right atrial pressure $(R A)$

\begin{tabular}{|c|c|c|c|c|c|}
\hline & Control $(n=10)$ & $\begin{array}{l}\text { Dopexamine dose } \\
1 \mu g / \mathrm{kg} / \min (n=10)\end{array}$ & $3 \mu \mathrm{g} / \mathrm{kg} / \min (n=10)$ & $6 \mu g / \mathrm{kg} / \min (n=8)$ & Significance $^{\star}$ \\
\hline $\begin{array}{l}\text { AP }(\mathrm{mm} \mathrm{Hg}): \\
\text { Systolic } \\
\text { Diastolic } \\
\text { Mean } \\
\text { PAP (mm Hg): }\end{array}$ & $\begin{array}{l}90(3) \\
64(4) \\
76(4)\end{array}$ & $\begin{array}{l}92(3) \\
63(4) \\
76(3)\end{array}$ & $\begin{array}{l}89(3) \\
59(4) \\
73(4)\end{array}$ & $\begin{array}{l}91(3) \\
60(4) \\
73(3)\end{array}$ & $\begin{array}{l}\text { NS } \\
\text { NS } \\
\text { NS }\end{array}$ \\
\hline $\begin{array}{l}\text { Systolic } \\
\text { Diastolic } \\
\text { Mean } \\
\text { LVEDP (mm Hg) } \\
\text { RA (mm Hg) }\end{array}$ & $\begin{array}{r}41(4) \\
22(3) \\
30(3) \\
23(3) \\
6(2)\end{array}$ & $\begin{array}{r}42(4) \\
21(2) \\
30(3) \\
20(3) \\
5(2)\end{array}$ & $\begin{array}{r}42(5) \\
19(5) \\
29(4) \\
17(3) \\
4(2)\end{array}$ & $\begin{array}{l}45(5) \\
20(4) \\
31(4) \\
18(3) \\
4.5(2)\end{array}$ & $\begin{array}{l}\text { NS } \\
\text { NS } \\
\text { NS } \\
p<0.01 \\
p<0.05\end{array}$ \\
\hline
\end{tabular}

*Statistical significance of treatment effect. NS, not significant. 
vascular resistance were both reduced from 2360 (277) dyn s $\mathrm{cm}^{-5}$ to $1204(267)$ dyn $\mathrm{s} \mathrm{cm}^{-5}$ $(p<0.001)$ and from 339(99) dyn s cm $\mathrm{cm}^{-5}$ to 261(82) dyn $\mathrm{s} \mathrm{cm}^{-5}(\mathrm{p}<0.01)$ respectively.

There were small reductions in both right and left heart filling pressures. Left ventricular end diastolic pressure was 23(3) $\mathrm{mm} \mathrm{Hg}$ at control and fell to 18(3) $\mathrm{mm} \mathrm{Hg}$ at the high dose. Mean right atrial pressure fell from 6(2) $\mathrm{mm} \mathrm{Hg}$ to $4.5(2) \mathrm{mm} \mathrm{Hg}(\mathrm{p}<0.05)$.

Left ventricular end diastolic and end systolic volume were both reduced by dopexamine from $388(33) \mathrm{cm}^{3}$ to $279(25) \mathrm{cm}^{3}(\mathrm{p}<0.05)$ and from $272(29) \mathrm{cm}^{3}$ to $195(23) \mathrm{cm}^{3}(\mathrm{p}<0.05)$ respectively. Ejection fraction was increased from $20(3) \%$ to $30(3) \%(p<0 \cdot 05)$.

\section{INDICES OF CONTRACTILITY}

The data for the various indices of contractility are shown in Fig. 3. The two isovolumic phase indices of myocardial contractility were both significantly increased during dopexamine infusion. $\mathrm{dP} / \mathrm{dt} \max$ rose from $646(50) \mathrm{mm} \mathrm{Hg} / \mathrm{s}$ at control to $847(86) \mathrm{mm}$ $\mathrm{Hg} / \mathrm{s}$ at the high dose $(\mathrm{p}<0.001)$. Similarly $\mathrm{KVmax}$ was increased from 65(4)s to 88(12)s $(p<0.01)$.

Technically satisfactory velocity signals were obtained in seven of the 10 patients studied. The ejection phase indices of contractility were all significantly increased by dopexamine administration $(p<0.01)$. Peak aortic blood velocity increased from a control value of $30(5) \mathrm{cm} / \mathrm{s}$ to $58(13)$ $\mathrm{cm} / \mathrm{s}$ at the high dose level. Maximum acceleration of blood during ejection rose from $520(123) \mathrm{cm} / \mathrm{s}^{2}$ to $965(257) \mathrm{cm} / \mathrm{s}^{2}$. The maximum rate of change of power with time (dPower/dt) was increased from 38(7) watts/s to 72(13) watts/s at the high dose.

Fig. 4 illustrates the relation between two of these indices of contractility $(\max \mathrm{dP} / \mathrm{dt}$ and $\mathrm{KVmax}$ ) and changes in heart rate. In only one patient at the low and intermediate dose levels was $\max \mathrm{dP} / \mathrm{dt}$ increased without concomitantly large increase in heart rate. KVmax was increased in four patients at the low dose level and in two of these four patients at the intermediate dose level without concomitantly large increase in heart rate.

CORONARY HAEMODYNAMICS AND MYOCARDIAL METABOLIC RESPONSES

The coronary sinus was successfully cannulated in eight of the 10 patients. The data for coronary haemodynamics and myocardial metabolic responses are shown in Tables 2 and 3. Dopexamine produced small statistically insignificant increases in coronary sinus flow and myocardial oxygen consumption and increased myocardial efficiency from $7(3) \%$ at control to $12(4) \%$ at the high dose level $(p<0.01)$.

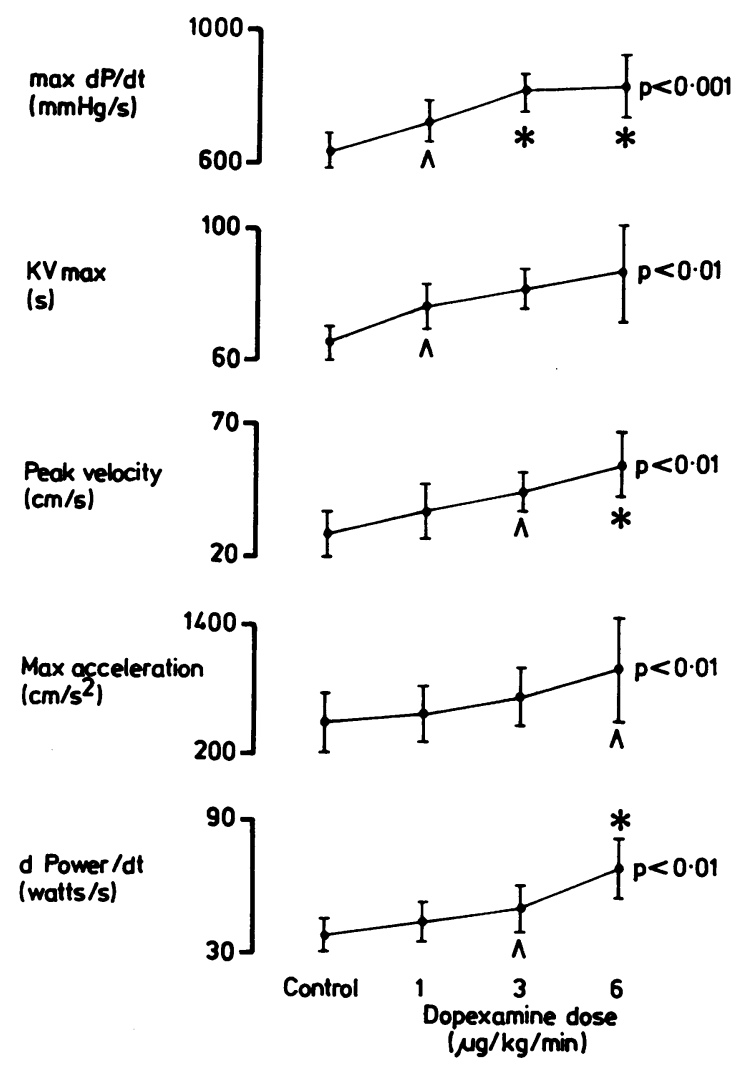

Fig. 3 Effect of treatment with three incremental doses of dopexamine on maximum $d P / d t, K V \max$, peak aortic blood velocity, maximum acceleration of blood during ejection, and dPower/dt. Significance of the treatment effect is shown. The arrow head indicates the first dose at which a change from control was significant $(p<0.05)$. Asterisks indicate when the effect of the dose was significantly different from the effect of a preceding dose $(p<0.05)$.

In the total group the arterial concentrations of lactate, pyruvate, ketone bodies, and glucose did not change appreciably with dopexamine administration but there was a significant increase in the arterial concentrations of glycerol and free fatty acids $(p<0.05)$. Dopexamine reduced the myocardial extraction of most substrates but this change was significant $(p<0.05)$ for free fatty acids only. During the control period two patients (one with coronary artery disease and one with congestive cardiomyopathy) were net myocardial producers of lactate. During dopexamine infusion the patient with coronary artery disease continued to produce lactate and another patient with coronary artery disease switched from being a net myocardial extractor of lactate to being a net producer of lactate, suggesting a change to anaerobic metabolism. The patient with 

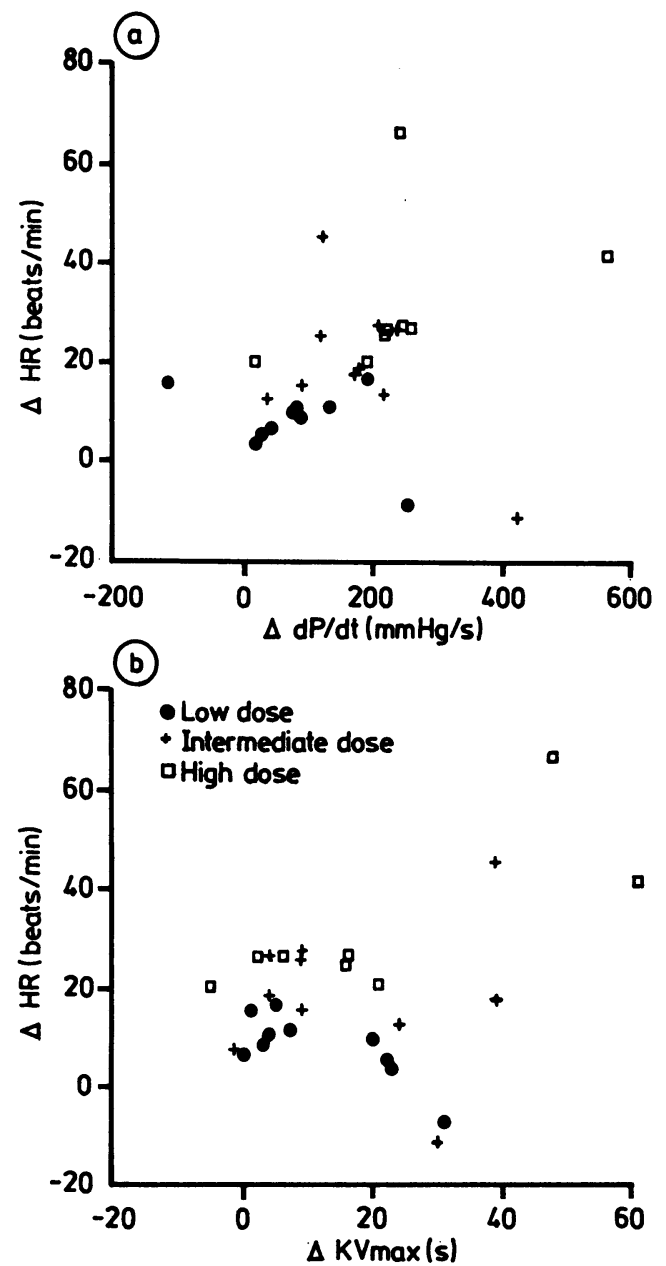

Fig. 4 Relation between change in heart rate and change in max $d P / d t(a)$ and change in $K V \max (b)$ in individual patients at low $(1 \mu \mathrm{g} / \mathrm{kg} / \mathrm{min})$, intermediate $(3 \mu \mathrm{g} / \mathrm{kg} / \mathrm{min})$, and high $(6 \mu \mathrm{g} / \mathrm{kg} / \mathrm{min})$ doses.

congestive cardiomyopathy became a net extractor of lactate during dopexamine infusion but another patient with congestive cardiomyopathy changed from being a net extractor of lactate to being a net producer of lactate during dopexamine infusion.

\section{ADVERSE REACTIONS}

The low $(1 \mu \mathrm{g} / \mathrm{kg} / \mathrm{min})$ dose was well tolerated by all patients. At the intermediate $(3 \mu \mathrm{g} / \mathrm{kg} / \mathrm{min})$ dose two patients reported the symptom of tremulousness at a time when both had pronounced haemodynamic responses. Therefore we did not give these two patients the high $(6 \mu \mathrm{g} / \mathrm{kg} / \mathrm{min})$ dose. Of the eight patients who were given the high dose, two patients (both with severe coronary artery disease) reported mild chest pain typical of angina pectoris but which did not interfere with data collection and which resolved rapidly after discontinuation of the drug. No arrhythmias were detected during the study.

\section{Discussion}

The aim of this study was to evaluate the acute effects of an intravenous infusion of dopexamine on haemodynamics and myocardial metabolic function in patients with chronic heart failure. The basal low values for cardiac index, stroke volume index, and ejection fraction and the high values for systemic vascular resistance and ventricular volumes testify to the severity of heart failure in the study group. The results of the study indicate that the drug has powerful dose related effects; principally to increase cardiac index (maximum increase $121 \%$ ) and stroke volume index (maximum increase $63 \%$ ), and to reduce systemic vascular resistance (maximum reduction $49 \%$ ) wihout altering pulmonary or aortic pressures. These changes, which are beneficial in patients with heart failure, occurred without a significant increase in myocardial oxygen consumption or alteration of myocardial metabolic function.

The pronounced reduction in systemic vascular resistance produced by dopexamine suggests that the drug has profound vasodilator properties; this accords with its postjunctional dopamine receptor stimulating and beta ${ }_{2}$ adrenoceptor agonist actions. Our results give no indication of the vascular beds on which the drug has its principal action, but the large number of postjunctional dopaminergic receptors in the renal vascular bed and their relative paucity in the femoral vascular bed suggest that much of the increased cardiac output may be directed to the kidneys. The small reductions observed in right and left ventricular filling pressures and pulmonary vascular resistance suggest that dopexamine has relatively little action on systemic capacitance vessels or on the pulmonary circulation and that its principal site of vasodilator action is the systemic arterial system (that is reduction of afterload).

Although all of the isovolumic and ejection phase indices of myocardial contractility were significantly increased by dopexamine, these findings must be interpreted with caution. The contractile state of the ventricle is modulated by preload, afterload, and heart rate. ${ }^{23}$ All of these changed during the study and such changes may therefore have been responsible for the apparent increase in the level of myocardial contractility. It is instructive to compare the results of this study with those of a previous study performed in our laboratory on the haemodynamic effects of the vasodilator sodium nitro- 
Table 2 Effects (mean $(S E)$ ) of an intravenous infusion of dopexamine at three incremental doses on coronary sinus flow $(C S F)$, myocardial oxygen consumption $\left(M_{V} \mathrm{O}_{2}\right)$, left ventricular minute work $(L V M W)$, and myocardial efficiency

\begin{tabular}{|c|c|c|c|c|c|}
\hline & Control $(n=8)$ & $\begin{array}{l}\text { Dopexamine dose } \\
1 \mu \mathrm{g} / \mathrm{kg} / \min (n=8)\end{array}$ & $3 \mu g / \mathrm{kg} / \min (n=8)$ & $6 \mu g / k g / \min (n=6)$ & Significance $^{\star}$ \\
\hline $\begin{array}{l}\mathrm{CSF}(\mathrm{ml} / \mathrm{min}) \\
\mathrm{MVO}_{2}(\mathrm{ml} / \mathrm{min}) \\
\operatorname{LVMW}(\mathrm{kg} / \mathrm{m} / \mathrm{min}) \\
\text { Efficiency }(\%)\end{array}$ & $\begin{array}{l}173(50) \\
22(7) \\
1 \cdot 6(0 \cdot 7) \\
7(3)\end{array}$ & $\begin{array}{l}198(64) \\
26(9) \\
2 \cdot 4(1) \\
7(2)\end{array}$ & $\begin{array}{c}173(41) \\
21(5) \\
3(0 \cdot 9) \\
9(4)\end{array}$ & $\begin{array}{l}229(56) \\
29(10) \\
4 \cdot 1(1 \cdot 2) \\
12(4)\end{array}$ & $\begin{array}{l}\text { NS } \\
\text { NS } \\
p<0.001 \\
p<0.01\end{array}$ \\
\hline
\end{tabular}

^Statistical significance of treatment effect. NS, not significant.

prusside in a similar group of patients with chronic heart failure. ${ }^{24}$ Sodium nitroprusside produced changes in preload and afterload which resembled those produced by dopexamine, but in contrast heart rate was not altered and the isovolumic phase indices of contractility maximum dP-dt and KVmax were unchanged. It could be argued that the increase in the indices of contractility observed in our patients treated with dopexamine were secondary to an increase in heart rate. Analysis of individual responses which compared changes in heart rate with changes in the isovolumic phase indices seems to confirm this assertion with respect to maximum $\mathrm{dP} / \mathrm{dt}$ (Fig. 4). There were several patients, however, in whom KVmax rose substantially at the low and intermediate doses without concomitant increases in heart rate (Fig. 4), a finding that may cautiously be interpreted as evidence that dopexamine has some direct positive inotropic action.

The striking increases in cardiac ouput observed in all patients were mediated through both an increase in stroke volume and an increase in heart rate. Inspection of Fig. 2 suggests that at the low dose the effect of a stroke volume increase predominated but at the intermediate and high doses increased heart rate was an important contributory factor to the improvement in cardiac output. The increase in heart rate produced by dopexamine may be due either to a direct positive chronotropic action (beta ${ }_{1}$ adrenoceptor mediated) or to a reflex tachycardia secondary to peripheral vasodilatation caused by the drug. We suggest that it is the former because when the "pure" vasodilator sodium nitroprusside was given to patients with heart failure there was a similar fall in systemic vascular resistance to that produced by dopexamine without a significant alteration in heart rate. ${ }^{24}$ Administration of a drug with a positive chronotropic action to patients with coronary artery disease is potentially deleterious because myocardial ischaemia may be induced either by increased myocardial oxygen consumption ${ }^{25}$ or by a reduction in coronary artery diastolic filling time.

The highly significant haemodynamic changes observed in our patients were associated with only a small and statistically insignificant rise in myocardial oxygen consumption. Myocardial oxygen consumption is determined by heart rate, the contractile state of the ventricle, and ventricular load. ${ }^{25}$ In our patients the positive chronotropic and possible positive inotropic effects of dopexamine would both be expected to increase myocardial oxygen consumption, but this effect has in the main been offset by other drug induced reductions in components of left ventricular load such as systemic vascular resistance and left ventricular volume and end diastolic pressure.

The effect of dopexamine on myocardial energetics can be examined by estimating myocardial

Table 3 Summary of metabolic results (mean $(S E)$ )

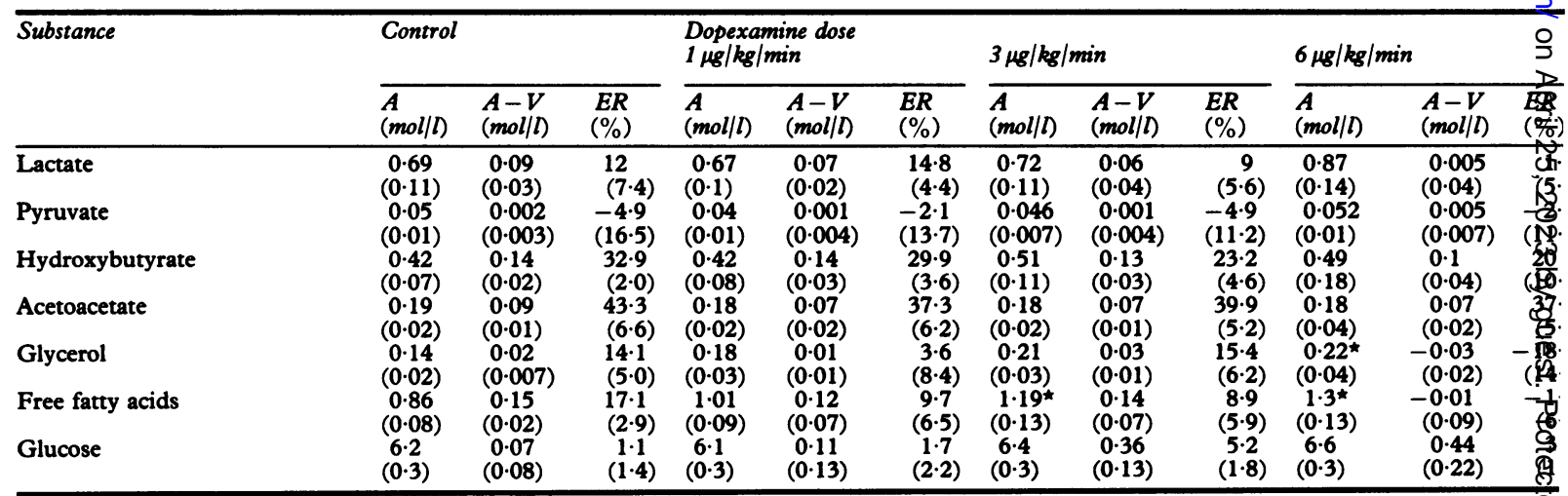

A, arterial concentration; A-V, arteriovenous concentration difference; ER, extraction ratio. ${ }^{\star}$ Significantly different from control value (p < 0.032 
efficiency, which relates the external work performed by the ventricle to myocardial oxygen consumption. In a normal heart myocardial efficiency is approximately $40 \%{ }^{2126}$ The very low basal value of $7 \%$ emphasises the severity of disturbance of myocardial energetics in our patients. Dopexamine significantly increased myocardial efficiency $(p<0.01)$ principally by an increase in external work performed by the left ventricle, since myocardial oxygen consumption was essentially unchanged. External work is determined by the extent of muscle shortening against load and therefore it can be inferred that many of the beneficial effects of dopexamine are due to favourable alterations in ventricular loading.

In most patients the pattern of myocardial substrate utilisation when control measurements were obtained was similar to results reported in the normal heart, ${ }^{27}$ but two patients (one with coronary artery disease and one with congestive cardiomyopathy) were net myocardial producers of lactate at rest and this indicates some degree of anaerobic metabolism. Dopexamine seemed to have no important actions on myocardial metabolic function; it had little effect on arterial concentrations, extraction, and extraction ratios of most of the substrates measured. The small increase in the arterial concentration of free fatty acids is probably related to both the lipoprotein lipase activating action of heparin ${ }^{28}$ and the effect of fasting before and during the study. The reduction in the extraction ratio of free fatty acids is difficult to interpret. It may be spurious, because the free fatty acid arteriovenous concentration difference was narrow, and therefore small errors in measuring concentrations would have had a large effect upon estimated extraction.

Dopexamine was well tolerated by the patients in this study and no arrhythmias were seen. Two patients reported tremor. This symptom has been described in similar groups of patients treated with beta adrenergic agonist drugs. ${ }^{2930}$ At the high dose level two of the patients with severe coronary artery disease experienced mild chest pain typical of angina pectoris at a time when both had substantial increases in heart rate $(>30 \%)$. One of these patients was a net myocardial producer of lactate at rest (extraction ratio $-23 \%$ ) and remained so at the high dose (extraction ratio $-6 \%$ ). The second patient was a myocardial extractor of lactate at rest, and the onset of chest pain was associated with evidence suggesting a switch to anaerobic myocardial metabolism (extraction ratio $-12 \%$ ). In neither of these two patients was the increase in myocardial oxygen consumption ( 4.7 and $2.3 \mathrm{ml} / \mathrm{min}$ ) at the high dose greater than in the group mean $(6.5 \mathrm{ml} / \mathrm{min})$ nor was the onset of chest pain associated with the development of electrocardiographic manifestations of myocardial ischaemia.

The study results indicate that dopexamine has many beneficial haemodynamic properties in patients with heart failure, although its positive chronotropic action may limit its use in patients with coronary artery disease in whom the relation between myocardial supply and demand may be precarious. The precise mode of action of the drug is uncertain but improved cardiac performance is probably due principally to its peripheral vasodilator properties, although it may also have a positive inotropic effect. Further clinical evaluation is required, particularly an assessment of the efficacy of dopexamine in the setting of acute pump failure and a direct comparison of its actions with those of dopamine.

\section{References}

1 Holzer J, Karliner JS, O'Rourke RA, Pitt W, Ross J Jr. Effectiveness of dopamine in patients with cardiogenic shock. Am $\mathcal{f}$ Cardiol 1973; 32: 79-84.

2 Goldberg LI. Drug therapy: dopamine. Clinical uses of an endogenous catecholamine. $N$ Engl f Med 1974; 291: 707-10.

3 McNay JL, Goldberg LI. Hemodynamic effects of dopamine in the dog before and after alpha adrenergic blockade. Circ Res 1966; 18 (suppl I): 110-9.

4 Goldberg LI. Cardiovascular and renal actions of dopamine: potential clinical applications. Pharmacol 1972; 24: 1-29.

5 Mueller HS, Evans R, Ayres SM. Effects of dopamine on hemodynamics and myocardial metabolism in shock following acute myocardial infarction in man. Circulation 1978; 57: 361-5.

6 Brown RA, Farmer JB, Hall JC, et al. FPL 60278: Actions at pre and post junctional dopamine receptors and at alpha and beta adrenoceptors [Abstract]. $\mathrm{Br} \mathcal{F}$ Pharmacol 1984; 81: 120P.

7 Brown RA, Farmer JB, Hall JC, Humphries RG, O'Connor SE, Smith GW. FPL 60278, novel agonist at peripheral dopamine receptors and beta-2 adrenoceptors: cardiovascular effects in the dog [Abstract]. Br 7 Pharmacol 1984; 81: 10P.

8 Thompson DS, Naqvi N, Juul SM, Coltart DJ, Jenkins BS, Webb-Peploe MM. Haemodynamic and metabolic effects of atenolol in patients with angina pectoris. $\mathrm{Br}$ Heart $\mathcal{F}$ 1980; 43: 668-79.

9 Robinson PS, Crowther A, Jenkins BS, Webb-Peploe MM, Coltart DJ. A computerised dichromatic earpiece densitometer for the measurement of cardiac output. Cardiovasc Res 1979; 13: 420-6.

10 Brooksby IAB, Swanton RH, Jenkins BS, WebbPeploe MM. Long sheath technique for introduction of catheter tip manometer or endomyocardial bioptome into left or right heart. Br Heart $\mathcal{f} 1974 ; 36$ : 908-12.

11 Reeves TJ, Heffner LL, Jones WB, Coghlan C, Prieto $\mathrm{G}$, Carroll J. The hemodynamic determinants of the rate of change of pressure in the left ventricle during isometric contraction. Am Heart $\mathcal{f} 1960$; 60: 745-61. 
12 Hugenholtz PG, Ellison RC, Urschel CW, Mirsky I, Sonnenblick EH. Myocardial force-velocity relationships in clinical heart disease. Circulation 1970; 41: 191-202.

13 Jewitt D, Gabe I, Mills C, Maurer B, Thomas M, Shillingford J. Aortic velocity and acceleration measurements in the assessment of coronary heart disease. Eur f Cardiol 1974; 1: 299-305.

14 Noble MIM, Trenchard D, Guz A. Left ventricular ejection in conscious dogs. 1. Measurement and significance of the maximum acceleration of blood from the left ventricle. Circ Res 1966; 19: 139-47.

15 Stein PD, Sabbah HN. Ventricular performance measured during ejection: studies in patients of the rate of change of ventricular power. Am Heart $\mathcal{F}$ 1976; 91: 599-606.

16 Horhorst HJ, Kreutz FH, Bucher T. Uber Metabolitgehalte und metabolit-konzentrationen in der Leber der Ratte. Biochemische Zeitschrift 1959; 332: 18-46.

17 Williamson DH, Mellanby J, Krebs AH. Enzymic determination of $\mathrm{D}(-)$ B-Hydroxybutyric acid and aceto-acetic acid in blood. Biochem $\mathcal{F}$ 1962; 82: 90-6.

18 Kreutz FH. Enzymatische Glycerinbeststimmung. Klin Wochenschr 1962; 40: 362-3.

19 Carruthers $M$, Young DAB. Free fatty acid estimation by a semi-automated fluorimetric method. Clin Chim Acta 1973; 49: 341-8.

20 Ganz W, Tamura K, Marcus HS, Donoso R, Yoshida S, Swan HJC. Measurement of coronary sinus blood flow by continuous thermodilution in man. Circulation 1971; 44: 181-95.

21 Bing RJ, Michal G. Myocardial efficiency. Ann NY
Acad Sci 1959; 72: 555-8.

22 Snedecor GW, Cochran WG. Statistical methods. 6th ed. Ames: Iowa State University Press, 1967: 272.

23 Furnival CM, Linden RJ, Snow HM. Inotropic changes in the left ventricle: the effect of changes in heart rate, aortic pressure and end-diastolic pressure. $\mathcal{f}$ Physiol (Lond) 1970; 211: 359-87.

24 Thompson DS, Juul SM, Wilmshurst P, et al. Effects of sodium nitroprusside upon cardiac work, efficiency, and substrate extraction in severe left ventricular failure. Br Heart $\mathcal{F} 1981$; $476394-400$.

25 Braunwald E. Control of myocardial oxygen consumption; physiologic and clinical considerations. $A m \mathcal{F}$ Cardiol 1971; 27: 416-32.

26 Thompson DS, Naqvi N, Juul SM, et al. Cardiac work and myocardial substrate extraction in congestive cardiomyopathy. Br Heart f 1982; 47: 130-6.

27 Bing RJ. Cardiac metabolism. Physiol Rev 1965; 45: 171-213.

28 Korn ED. Clearing factor; a heparin-activated lipoprotein lipase. I. Isolation and characterization of the enzyme from normal rat heart. $\mathcal{F}$ Biol Chem 1955; 215: 1-14.

29 Dawson JR, Canepa-Anson R, Kuan P, Reuben SR, Poole-Wilson RA, Sutton GC. Symptoms, haemodynamics, and exercise capacity during long-term treatment of chronic heart failure. Experience with pirbuterol. Br Heart $\mathcal{F}$ 1983; 50: 282-9.

30 Mifune J, Karamoto K, Ueda K, et al. Hemodynamic effects of salbutamol, a long-acting beta-stimulant, in patients with congestive heart failure. Am Heart f 1982; 104: 1011-5. 